\title{
Abcc10 status affects mammary tumour growth, metastasis, and docetaxel treatment response
}

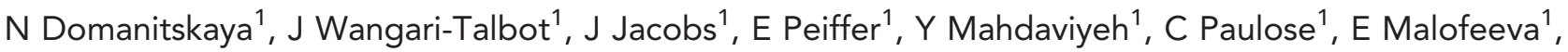 \\ $\mathrm{K}_{\text {Foster }}{ }^{1}, \mathrm{~K}$ Q Cai ${ }^{1}$, Y Zhou ${ }^{1}, \mathrm{~B}$ Egleston ${ }^{1}$ and E Hopper-Borge ${ }^{*, 1}$ \\ ${ }^{1}$ Program in Developmental Therapeutics, Fox Chase Cancer Center, Philadelphia 19111, PA, USA
}

\begin{abstract}
Background: Resistance to chemotherapeutic agents is a major obstacle to cancer treatment. A group of ABC efflux pumps, the Multidrug Resistance Proteins, is a source of resistance. Herein, we investigated the role of ABCC10 in mammary tumours, given the important role we have defined for $\mathrm{ABCC} 10$ in transporting taxanes, and the recognition that some $\mathrm{ABCC}$ proteins have roles in tumour growth.
\end{abstract}

Methods: $A B C C 10$ expression was correlated to human breast cancer subtype using breast tissue microarrays. Real-time quantitative PCR and western blot analysis were used to examine ABCC10 expression in human breast cancer lines. Abcc10-/mice were crossed to MMTV-PyVmT mice to produce $\mathrm{Abcc10}^{-/-}$vs $\mathrm{Abcc10^{+/+ }}$ mammary tumours and derivative cell lines. We used allograft and cellular assays to perform baseline and drug sensitization analysis of tumours and cell lines.

Results: Clinical sample analyses indicated that ABCC10 was more highly expressed in Her2 + and ER + than in Her2 - , ER - ,

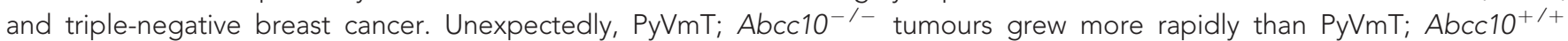
tumours and were associated with significantly reduced apoptosis and metastasis. PyVmT; $A b c c 10^{-/-}$lines were less migratory than PyVmT; Abcc10 ${ }^{+/+}$lines. Finally, we showed increased survival of docetaxel-treated MMTV-PyVmT; Abcc10 ${ }^{-/-}$mice compared with wild-type mice.

Conclusions: These data identify roles for Abcc10 in breast cancer pathogenesis and in vivo docetaxel resistance.

Much of the mortality of any cancer is associated with resistance to therapeutic agents. Docetaxel and paclitaxel have been mainstays of breast cancer treatment regimens and the development of chemotherapeutic resistance to these agents has long been a major impediment to cancer treatment. One reported contributing factor to multidrug resistance is the overexpression of a class of efflux pumps known as ATP-Binding Cassette (ABC) transporters. The C subfamily of $\mathrm{ABC}$ proteins, alternatively known as the $\mathrm{ABCC}$ proteins, or the Multidrug Resistance Protein subfamily, consists of nine family members. These pumps confer resistance to and transport several classes of chemotherapeutics including taxanes, vinca alkaloids, and anthracyclines, as well as physiological substrates including leukotrienes (Glavinas et al, 2004; Keppler, 2011).
Taxanes are important agents in the treatment of many cancers, including breast cancer (Woodward and Twelves, 2010). Wellstudied taxane pumps such as ABCB1 have been highly investigated over the past few decades as possible mediators of taxane resistance in breast cancer. To date, numerous studies have been unable to find a clinical benefit of inhibiting ABCB1 (Kelly et al, 2012; Amiri-Kordestani et al, 2013).

By contrast, although we and others have demonstrated that ABCC10 expression is widespread (Hopper et al, 2001; Wang et al, 2009), few studies have addressed the role of this protein in in vivo treatment resistance. ABCC10 is a particularly interesting transporter to study, as overexpression of ABCC10 in vitro confers resistance to an unusually wide range of clinically valuable drugs,

*Correspondence: Dr E Hopper-Borge, E-mail: Elizabeth.Hopper@fccc.edu

Revised 1 April 2014; accepted 13 May 2014;

published online 17 June 2014

(c) 2014 Cancer Research UK. All rights reserved 0007-0920/14

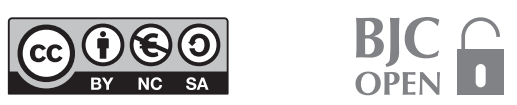


including taxanes, vinca alkaloids, nucleoside analogues, and epothilone B (Hopper-Borge et al, 2004; Oguri et al, 2008; Hopper-Borge et al, 2009). Excitingly, we used a newly developed $A b c c 10^{-/-}$mouse model to show that absence of this transporter in vivo sensitises animals to taxanes, with $A b c c 10^{-/-}$mice experiencing increased sensitivity (that is, increased neutropenia and bone marrow hypoplasia) compared with their wild-type counterparts following paclitaxel treatment (Hopper-Borge et al, 2011). These findings also suggest that modulation of ABCC10 activity by inhibitors may have clinical value in management of breast cancer and other cancers that are treated with taxanes, based on action in eliminating these drugs from breast tumour tissue.

Besides direct action in regulating drug efflux, a growing and intriguing body of work suggests that some $\mathrm{ABC}$ transporters may affect cancer biology in additional ways that affect disease course or treatment. A recent study has implied a link between ABCC1, $\mathrm{ABCC} 11$, and poor prognosis in breast cancer (Yamada et al, 2013). ABCC1, ABCC3, and ABCC4 have clinical and biological effects in neuroblastoma independent of their abilities to efflux drug (Henderson et al, 2011). For all of these transporters, expression tends to increase with age, causing them to be more abundant at the time of great rates of cancer onset. Interestingly, ABCC1 suppresses neuroblastoma development in an $h M C Y N$ mouse model. In vitro inhibition of $\mathrm{ABCC} 1$ and $\mathrm{ABCC} 4$ suppresses wound closure, whereas ABCC3 overexpression inhibits cell migration and cell line clonogenicity (Henderson et al, 2011). Such unexpected activities might also affect drug resistance, by affecting the proliferation rate of tumours, or by contributing to epithelial-mesenchymal transitions that are associated with general drug resistance (Dave et al, 2012; McMillin et al, 2013).

To date, few studies have addressed the impact of ABCC10 in breast cancer. One recent study showed that $A B C C 10$ mRNA is upregulated in breast carcinoma and that its expression correlates with ER status (Hlavac et al, 2013). We have now examined the expression of the ABCC10 protein in breast tumours and breast cancer cell lines to establish physiological relevance in this context. To further investigate the role of ABCC10 in breast cancer, and in particular the viability of $\mathrm{ABCC} 10$ as a target for cancer treatment, we have also bred Abcc10 $10^{-/-}$mice to the well-described mouse mammary tumour virus-polyomavirus middle T (MMTV-PyVmT) model (Lin et al, 2003). We chose this model because detailed pathological analysis of PyVmT tumours indicates that the progression from premalignant to highly malignant stages is very similar to that seen in human breast tumours (Lin et al, 2003). Together, our data showed for the first time that ABCC10 affects multiple parameters of breast tumour biology and may modulate the efficacy of docetaxel to treat tumours.

\section{MATERIALS AND METHODS}

Cell lines. HS578T, BT549, T47D, MDA-MB-231 human breast cancer cell lines were purchased from the National Cancer Institute (Bethesda, MD, USA). MCF10F, MCF7, BT474, SKBR-3, MDAMB-361 human breast cancer cell lines were purchased from the American Type Culture Collection (ATCC). Cells were passaged in our laboratory for fewer than 3 months after receipt or resuscitation.

Reagents. $\left[{ }^{3} \mathrm{H}\right]$-docetaxel $\left(5 \mathrm{Ci} \mathrm{mmol}^{-1}\right.$; Moravek Biochemicals Inc, Brea, CA, USA). Docetaxel was purchased from LC Laboratories (Woburn, MA, USA). Paclitaxel was purchased from Sigma (St Louis, MO, USA).

Mouse strains, handling and measurement of tumours. All experiments involving mice were preapproved by the Fox Chase Cancer Center Institutional Animal Care and Use Committee. MMTV-PyVmT mice of the 634Mul/J subline were purchased from The Jackson Laboratory (Bar Harbor, ME, USA). Homozygous $\mathrm{Abcc10}^{-/-}$mice (Hopper-Borge et al, 2011) were crossed with MMTV-PyVmT mice to generate the $A b c c 10^{-/-}$; PyVmTpositive and Abcc10 $0^{+/+}$PyVmT-positive female siblings for analysis. We have confirmed that Abcc10 is lost in this model at the RNA and protein levels. Tumour volumes were calculated following caliper measurement as width $^{2} \times$ length $\times 0.52$. Mice were killed by methoxyfluorane inhalation when the tumours reached $10 \%$ of mice body weight or if mice exhibited signs of illness or distress.

Xenograft studies. MMTV-PyVT;Abcc10 $0^{+/+}$and MMTVPyVT;Abcc $10^{-1-}$ mammary tumour-derived cells were implanted into the mammary gland area of 8 -week-old female SCID mice ( $n=15$ per cell line). Two weeks later, when the tumours grew to $\sim 50 \mathrm{~mm}^{3}$, the mice were divided into two groups: vehicle $(n=5)$ and $25 \mathrm{mg} \mathrm{kg}^{-1}$ docetaxel treatment $(n=10)$. To evaluate tumours, a very dense measuring technique was used to assess solid tumour mass and to reduce the volume added from liquid. The mice were treated weekly by intraperitoneal injection until the tumours reached the maximum size $\left(200 \mathrm{~mm}^{3}\right)$; at the end of the experiment mice were killed by methoxyfluorane inhalation.

Immunohistochemical analysis. The largest tumour and lungs were excised, divided, and fixed $24-48 \mathrm{~h}$ in $10 \%$ neutral-buffered formalin. Specimens were paraffin-embedded, sectioned, and analysed with haematoxylin/eosin staining. Consecutive $5-\mu \mathrm{m}$ sections were cut and mounted on silinized slides (Superfrost Plus, Fisher Scientific Inc., Waltham, MA, USA). Sections were deparaffinised in xylene and rehydrated in a graded series of ethanol. The sections were subjected to antigen retrieval by boiling in $0.01-\mathrm{M}$ sodium citrate buffer $(\mathrm{pH} 6.0)$ in a steamer for $20 \mathrm{~min}$ and allowed to cool in the buffer for $20 \mathrm{~min}$. Immunostaining was performed by standard protocols previously described (Cai et al, 2009). All slides were viewed with a Nikon Eclipse 50i microscope and photomicrographs were taken with an attached Nikon DS-Fi1 camera (Melville, NY, USA). Lung metastases were expressed as number of metastases per square millimetre of lung cross-section using Image Pro-Plus (Media Cybernetics, Silver Spring, MD, USA). Immunostained slides (for Ki-67) were scanned using an Aperio ScanScope CS 5 slide scanner (Aperio, Vista, CA, USA) with a $\times 40$ objective. Scanned images were then viewed with Aperio's image viewer software (ImageScope, version 11.1.2.760, Aperio). Selected regions of interest were outlined manually by a pathologist. Proliferative index (Ki-67) was quantified using Aperio Nuclear V9 algorithm (Aperio) with modifications.

Tissue microarray (TMA). A breast TMA was constructed as previously described (Kononen et al, 1998; Parsons, 2009). The intensity of immunostaining using a monoclonal ABCC10 antibody (Hopper-Borge et al, 2009) was scored visually by an experienced pathologist. For certain statistical analyses, absence of $\mathrm{ABCC} 10$ staining was considered to be one group and presence of ABCC10 staining was considered to be another group.

Derivation of mammary tumour cells and cellular assays. Cell lines were derived as previously described (Izumchenko et al, 2009). Drug accumulation assay was performed as previously described (Hopper-Borge et al, 2004). Proliferation was quantitated with CyQuant (Invitrogen, Eugene, OR, USA) according to the manufacturer's instructions and adhesion of cells was monitored by the xCELLigence Real-Time Cell Analysis detection platform (ACEA Bioscience Inc., San Diego, CA, USA). Cellular proliferation assays with HEK-293 cells were performed as previously described (Hopper-Borge et al, 2009). To analyse change of mammary tumours, cell line shape factor after drug treatment cells were stained for phalloidin-FITS-conjugated, 4',6-diamidino-2phenylindole (DAPI) and Deep Red Cell Mask. Image quantitative analysis was performed with the MetaXpress 3.1 software 
(MDS Analytical Technologies, Sunnyvale, CA, USA). Confocal laser scanning microscopy was performed as previously described (Malofeeva et al, 2012). Cell cycle and apoptosis analyses were assessed using Guava Nexin and cell cycle reagents (Guava Technologies, Hayward, CA, USA) according to the manufacturer's protocol. For all cytotoxicity experiments, treatment of Abcc10 knockout and wild-type cells was started after the cells were attached completely.

Colony formation and wound-healing assays. PyVmT; $A b c c 10^{+/+}$ and PyVmT; $A b c c 10^{-/-}$mammary tumour cell lines were seeded at low density in individual wells of a standard six-well plate and treated with docetaxel or paclitaxel for 5 days. Colonies were visualised with crystal violet staining. For wound-healing assays, cell-free areas were generated with a pipette tip on a confluent monolayer. Cells were treated with docetaxel $(3 \mathrm{nM})$ or paclitaxel $(3 \mathrm{nM})$. Two or three wound areas per condition were photographed at 8 or $24 \mathrm{~h}$. Wound size was quantified by measuring the cell-free areas using the Image- $J$ software (NIH, Bethasda, MD, USA).

Quantitative real-time PCR. Total RNA was isolated using the RNeasy mini kit (Qiagen, Valencia, CA, USA) according to the manufacturer's suggestions. RNA was reverse-transcribed using the M-MLV reverse transcriptase and a mixture of anchored oligo-dT primers and random decamers. Aliquots of cDNA were used for qRT-PCR. Cycling conditions were $95^{\circ} \mathrm{C}, 15 \mathrm{~min}$ followed by 40 cycles $\left(95^{\circ} \mathrm{C}, 15 \mathrm{~s} ; 60{ }^{\circ} \mathrm{C}, 60 \mathrm{~s}\right)$. To compare transporter expression levels, all mean quantity data were normalised to an independent gene Ppib (cyclophilin B).

Western blot analysis. Western blot analysis was performed as described (Izumchenko et al, 2009). Anti-Abcc10 antibody was used at a concentration of 1:500 (Hopper-Borge et al, 2011). ABCB1, ABCG2 (Santa Cruz Biotechnology, Dallas, TX, USA), $\beta$-actin (Abcam, Cambridge, MA, USA), HER2 and ER $\alpha$ (Cell Signalling Technology, Danvers, MA, USA) antibodies were used according to the manufacturer's instructions.

Statistical procedures. We used Fisher's exact tests for Figure 1C. We used Kaplan-Meier curves with log-rank tests for Figures 2A and 7C. We used generalised linear models estimated by generalised estimating equations with appropriate working correlation matrices for Figures 2B, 6A, 7A and B (Shults et al, 2007). We used restricted cubic splines to model day effects where there were enough days to do so (Harrell, 2001). The previous analyses were conducted using STATA (StataCorp, College Station, TX, USA). For Supplementary Figure 1 data from two data sets were background-corrected and RMA-normalised (Bolstad et al, 2003), then LIMMA methodology (Smyth, 2004) was applied to conduct the differential analysis between tumour and normal tissues. For other analyses, we used two-sided Student's $t$-tests. Error bars in figures represent one s.e. intervals, unless otherwise noted. The nominal criteria for statistical significance was set to $P<0.05$.

\section{RESULTS}

Elevated ABCC10 protein expression in human HER2 + and ER + breast cancer. A prior study examined ABCC10 expression at the mRNA level using the NCI panel cell lines (Szakacs et al, 2004). As a way to ascertain the ABCC10 protein expression levels in breast cancer, we examined eight well-characterised breast cancer-derived cell lines and one nontumorigenic breast epithelial cell line as a control. Other groups have previously shown that HER2 and ER expression positively correlates with taxane resistance (Ueno et al, 1997; Sui et al, 2007) and we decided to analyse the expression of ABCC10 in the context of ER and HER2 status of the cell lines. We determined that ABCC10 was expressed in all cell lines and was expressed most highly in MCF7, T47D, and
BT474 cell lines (Figure 1A). In contrast, HS578T, BT549, and MDAMB-231, all triple-negative cell lines expressed the lowest levels of $\mathrm{ABCC} 10$. Upon further analysis, we determined that ABCC10 expression was higher in HER2-positive cell lines compared with HER2-negative cell lines (Figure 1B and Supplementary Figure 1). However, greater significance was observed in the ABCC10 expression levels of ER-positive lines compared with ER-negative lines (Figure 1B and Supplementary Figure 1). We also analysed ABCC10 mRNA level in two breast cancer data sets from Gene Expression Omnibus (GSE5764 and GSE8977). ABCC10 expression was significantly higher in tumour than in normal lobular breast tissue in contrast to $A B C B 1$ and $A B C G 2$ expression (Supplementary Figure 2). We developed and screened TMAs containing 51 (Figure 1C and D) breast cancer specimens, including 18 HER2 +, 15 HER2 - , and 18 triple-negative (ER - /PgR - /HER2 - ) samples; we chose these breast cancer subtypes to focus on primarily because they are treated with chemotherapeutic agents that are ABCC10 substrates. We found that ABCC10 expression correlated positively with HER $2+$ and surprisingly ER + status. In addition, using HEK-ABCC10 transfectants (Hopper-Borge et al, 2009) we found that $\mathrm{ABCC} 10$ did not confer cellular resistance to tamoxifen, the agent used primarily to treat ER + breast cancer (Higgins and Baselga, 2011). In these standard proliferation assays $(n=7)$ we found the $\mathrm{IC}_{50}$ for the control cell line HEK-293 to be $187.5 \pm 23.6 \mu \mathrm{M} v s$ for the ABCC10 transfectant lines, $202 \pm 21.6 \mu \mathrm{M}$ for HEK-ABCC10-C17 and 190.4 $\pm 26.0 \mu \mathrm{M}$ for HEK-ABCC10-C18. We observed that $\mathrm{ABCC} 10$ was expressed mainly in the cytoplasm and membrane. In addition, triple-negative breast cancer subtype showed higher heterogeneity for ABCC10 expression compared with other cancer subtypes $(38.9 \%$ of ER - /PgR - /HER2 - samples did not express ABCC10 vs $6.7 \%$ and $0 \%$ for HER2 - and HER2 + breast cancer subtypes, respectively, Figure 1C). We also noted a tendency towards increased ABCC10 expression with age (Supplementary Table 1).

Mammary tumour growth is enhanced in MMTVPyVmT;Abcc10 ${ }^{-1-}$ vs MMTV-PyVmT;Abcc10 ${ }^{+/+}$mice. To understand the role of Abcc10 in mammary tumours in a physiological context, we bred $A b c c 10^{-/-}$mice (Hopper-Borge et al, 2011) to mice expressing the MMTV-PyVmT transgene. The MMTV-PyVmT mouse mammary model (Guy et al, 1992) has been used in numerous publications in the past (Forrester et al, 2005; Izumchenko et al, 2009; Marcotte et al, 2012; Ishihara et al, 2013). Latency until detection of mammary tumours was comparable in MMTV-PyVmT; Abcc10 $10^{-1-}$ and MMTV-PyVmT; $A b c c 10^{+/+}$mice (Figure $2 \mathrm{~A}$ ). $\mathrm{Abcc10} 0^{+1+}$ status, however, significantly limited the total tumour burden of MMTV-PyVmT mice. After 20 weeks, tumours derived from MMTV-PyVmT; $A b c c 10^{-1-}$ animals reached an average volume of $1000 \mathrm{~mm}^{3}$, whereas tumours derived from MMTV-PyVmT; $A b c c 10^{+/+}$mice had an average volume of $300 \mathrm{~mm}^{3}$ ( $P=0.020$; Figure $2 \mathrm{~B}$ ). Given this result, it was surprising that after killing, histopathological analysis revealed that MMTV-PyVmT; $A b c c 10^{+/+}$and MMTVPyVmT; $A b c c 10^{+/-}$tumours were less differentiated than MMTV-PyVmT; Abcc10 $0^{-/-}$tumours $(P=0.030$; Supplementary Table 2), as less differentiated tumours are typically more aggressive, metastasise early, and have a much poorer prognosis (Soerjomataram et al, 2008). Quantification of blood vessel density with CD31 staining showed a trend towards higher vascularisation of MMTV-PyVmT; $A b c c 10^{+/+}$tumours, and Caspase 3 staining indicated a higher rate of apoptosis in wild-type tumours compared with Abcc10 null tumours (Figure 2C). Interestingly, increased Caspase 3 activity correlates with a worse prognosis (O’Donovan et al, 2003). Analysis of lungs from mice bearing primary mammary tumours indicated greater levels of metastasis in MMTV-PyVmT; Abcc10 $0^{+/+}$tumours compared with MMTVPyVmT; Abcc10 $0^{-/}$tumours (Figure 2D). 
A

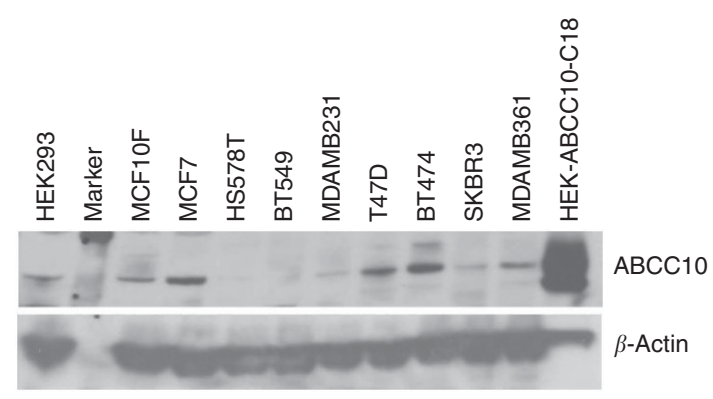

C

Variable $\quad \mathrm{N} \quad \mathrm{ABCC} 10$ score $P$-value

\begin{tabular}{|c|c|c|c|c|}
\hline & \multicolumn{2}{|c|}{ Negative $N(\%)$} & sitive $N(\%)$ & \\
\hline Total & 51 & 8 & 43 & \\
\hline ER & & & & 0.117 \\
\hline Positive & 22 & $1(4.5)$ & $21(95.5)$ & \\
\hline Negative & 29 & $7(24)$ & $22(76)$ & \\
\hline HER2 & & & & 0.039 \\
\hline Positive & 18 & $0(0)$ & $18(100)$ & \\
\hline Negative & 33 & $8(24)$ & $25(76)$ & \\
\hline Molecular profile & & & & 0.002 \\
\hline ER-/PgR-/HER-2- & 18 & $7(38.9)$ & $11(61.1)$ & \\
\hline HER-2- & 15 & $1(6.7)$ & 14 (93.3) & \\
\hline HER-2+ & 18 & $0(0)$ & $18(100)$ & \\
\hline
\end{tabular}

D
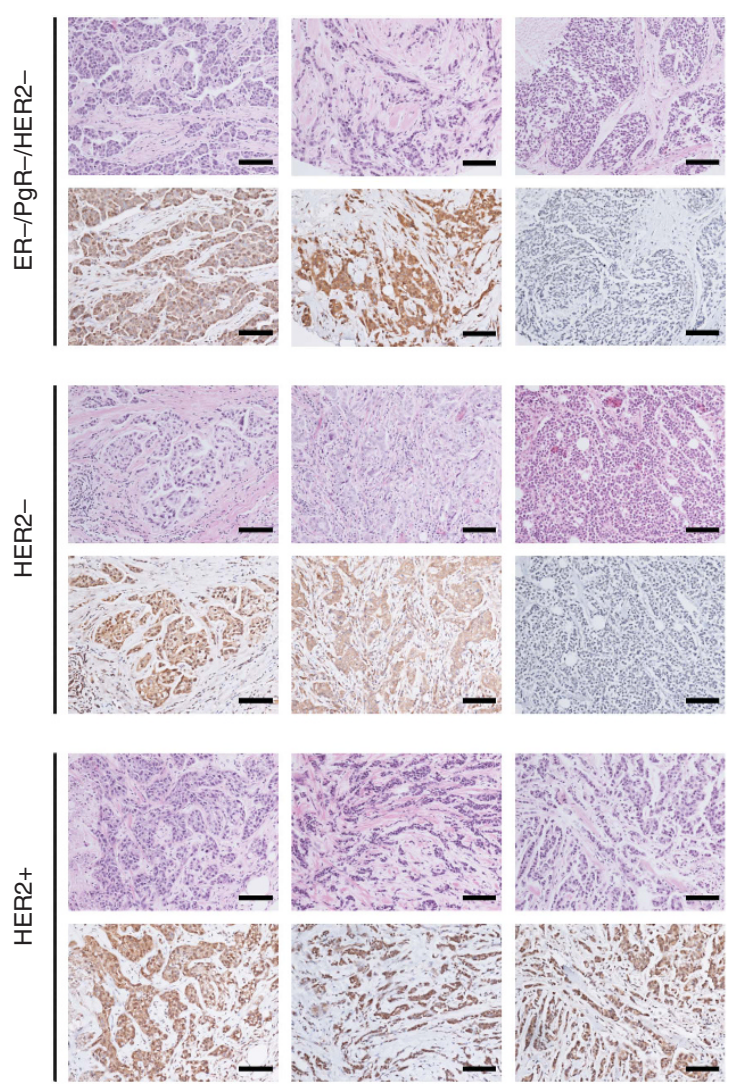

Figure 1. ABCC10 expression in human breast cancer cell line and primary tumours. (A) Top, western blot showing $A B C C 10$ protein levels in nontumorigenic epithelial cell lines, HEK-293 and MCF10F, human breast cancer lines MCF7, HS578T, BT549, MDA-MB-231, T47D, BT474, SKBR-3, and MDA-MB-361. An ABCCC10-overexpressing HEK transfectant (HEK-ABCC10-C18) was used as a positive control. Bottom, relative ABCC10 expression from three separate blots. (B) ABCC10 expression in HER2 - (MCF7, HS578T, BT549, MDA-MB-231, and T47D), HER2 + cell lines (BT474, SKBR-3, and MDA-MB-361), ER - (HS578T, BT549, MDA-MB-231, and SKBR-3) ER + (MCF7, T47D, BT474, and MDA361), and triple-negative (TNBC) (HS578T, BT549, MDA-MB-231). (C, D) Correlation of ABCC10 expression with HER2 status, ER status, and with the triple-negative breast cancer subtype was determined using immunohistochemical analysis of 51 human breast tumours. Scale bar, $100 \mu \mathrm{m}$. Error bars denote mean \pm s.e.m. Statistical significance was determined by two-sided Student's $t$-test.

Abcc10 status affects the growth of mammary tumour-derived cell lines. To better understand ABCC10-mediated effects on cancer progression and drug resistance, we derived MMTVPyVmT; Abcc10 ${ }^{-1-}$ and MMTV-PyVmT; Abcc10 $0^{+/+}$tumour cell lines (Figure $3 \mathrm{~A}$ ). We found that the rate of proliferation of MMTV-PyVmT; Abcc10 $0^{+/+}$cells was initially comparable to that of MMTV-PyVmT; $A b c c 10^{-/-}$cells; however, 6 days after plating, MMTV-PyVmT; $A b c c 10^{-1-}$ had an increased proliferation rate (Figure 3B). To ascertain whether adhesion had a role in the growth rate differences between PyVmt;Abcc10 $0^{+/+}$and PyVmT;Abcc10 $0^{-1-}$ mammary tumour-derived cell lines, we seeded cells and allowed attachment for $24 \mathrm{~h}$. By $24 \mathrm{~h}$ all knockout cells attached, in contrast fewer Abcc10 wild-type cells were attached at this time point (Figure $3 \mathrm{C}$ ). This result was confirmed by real-time monitoring of cell adhesion and spreading with xCELLigence system over a 24 -h period (Figure 3D). A colony formation assay revealed that MMTV-PyVmT; $\mathrm{Abcc10^{-/- }}$ cells formed threefold larger foci than MMTV-PyVmT; Abcc10 $10^{+/+}$ 

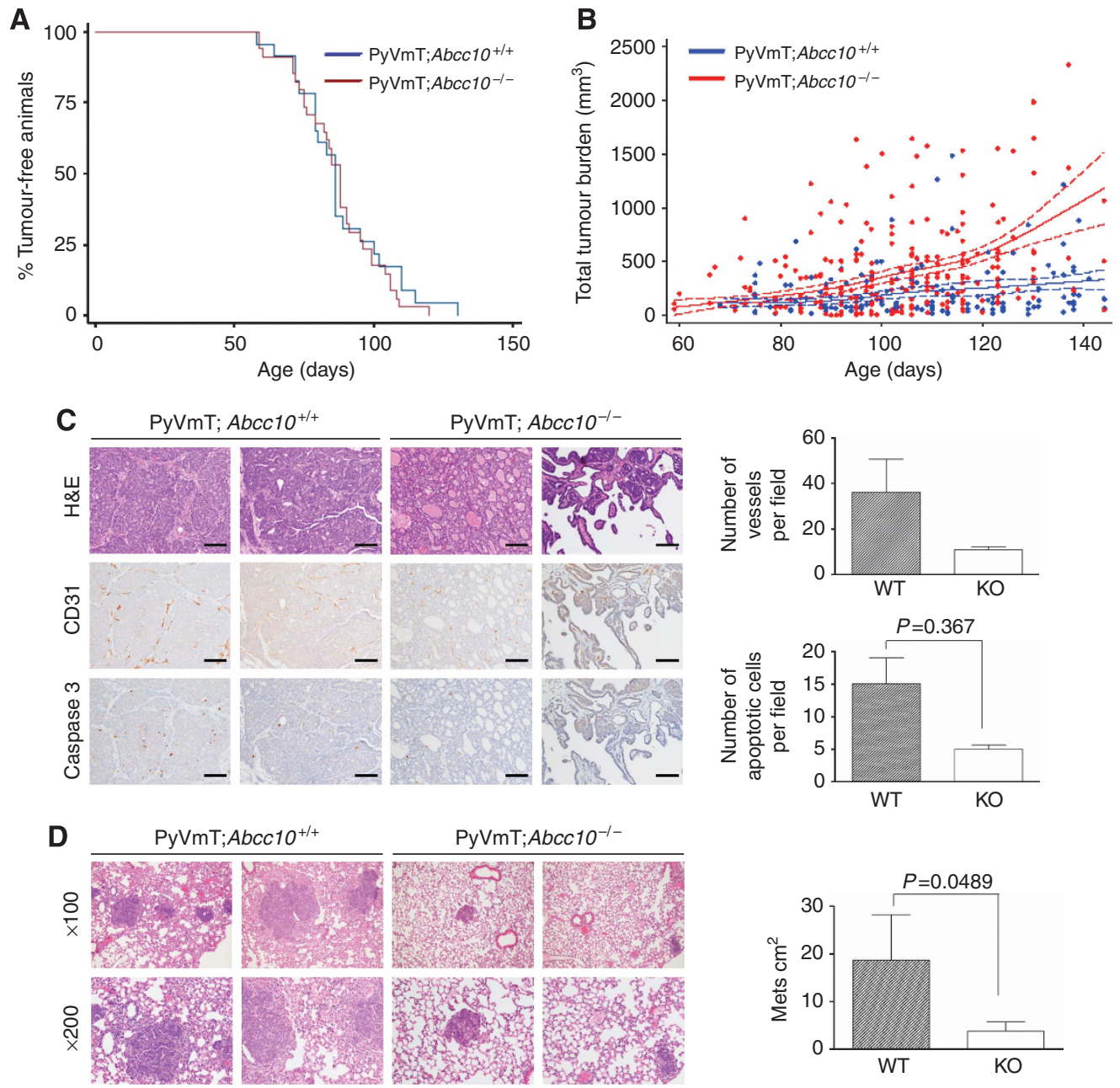

Figure 2. Tumour development in MMTV-PyVmT mice with $A b c c 10^{-/-}$and $A b c c 10^{+/+}$genotypes. (A) Kaplan-Meier curve analysis did not indicate significant differences in timing of tumor incidence in MMTV-PyVmT; Abcc10 ${ }^{-/-}$(red line; $\left.n=26\right)$ vs MMTV-PyVmT; Abcc10 ${ }^{+/+}($blue line; $n=21$ ) mice. (B) Comparison of growth rates of MMTV-PyVmT; Abcc10 ${ }^{-/-}$mammary tumours and MMTV-PyVmT; Abcc10 ${ }^{+/+}$tumours. (C) H\&E, CD31, and Caspase 3-stained sections of tumours isolated from MMTV-PyVmT;Abcc10 ${ }^{+/+}$and MMTV-PyVmT; Abcc10 ${ }^{-/-}$mice ( $n=5$ per genotype). Scale bar, $100 \mu \mathrm{m}$. (D) H\&E-stained lung sections isolated from MMTV-PyVmT; Abcc10 ${ }^{+/+}$and MMTV-PyVmT; Abcc10 ${ }^{-/-}$ mice. Error bars denote mean \pm s.e.m. Statistical significance was determined by two-sided Student's t-test.

cells (Figure 3E). Further, MMTV-PyVmT; $A b c c 10^{-/-}$cells are significantly larger than MMTV-PyVmT; $A b c c 10^{+/+}$cells (Figure 3F). Finally, a wound-healing assay was used to assess differences in migration of Abcc10 wild-type and null cell lines. We found that $24 \mathrm{~h}$ post scratch, MMTV-PyVmT; Abcc10 $10^{-1-}$ cells migrated $\sim 40 \%$ less compared with MMTV-PyVmT; Abcc10 $0^{+/+}$ cells (Figure 3G).

We assessed whether other transporters were modulated as a result of Abcc10 loss. mRNA expression of Abcc1, Abcc3, Abcc4, $A b c c 5, A b c b 1 a / b$, and Abcg2 was not elevated to compensate for Abcc10 loss (Supplementary Figure 3). Interestingly, there was a significant downregulation of Abcg2 in $\mathrm{Abcc10} 0^{-/}$cell lines compared with Abcc10 ${ }^{+1+}$ cells (Figure $3 \mathrm{H}$ ). However, a reduced level of Abcg2 in Abcc10 $0^{-/-}$cell lines would likely not have an impact on taxane sensitization as the class of taxanes is not an abcg2 substrate (Huisman et al, 2005).

MMTV-PyVmT;Abcc10 ${ }^{-/-}$mammary tumour cells are sensitised to taxanes. We used the well-established colony formation assay to assess taxane cytotoxicity on the primary tumour lines as previously described (Grassilli et al, 2013; Kuo et al, 2006). A 5-day treatment with $3 \mathrm{~nm}$ paclitaxel did not affect foci formation in MMTV-PyVmT; $A b c c 10^{+/+}$ cell lines while decreasing formation by more than $20 \%$ in
MMTV-PyVmT; Abcc10 $10^{-/-}$cell lines. Similarly, in MMTVPyVmT; Abcc10 ${ }^{+/+}$cells, treatment with 3 nm docetaxel produced $45 \%$ fewer colonies $v s$ vehicle-treated cells but $90 \%$ fewer colonies in MMTV-PyVmT; Abcc10 ${ }^{-1-}$ cells (Figure 4A).

In addition, incubation with taxanes affected the morphology of Abcc10 null cells more dramatically than Abcc10 wild-type cells. Analysis of phalloidin, DAPI, Deep Red Cell Mask staining with a fluorescence microscopy showed a significant change in the cell shape factor of MMTV-PyVmT; $A b c c 10^{-/-}$cell lines after paclitaxel or docetaxel treatment (Supplementary Figure 4). Docetaxel is a microtubule-stabilizing agent: we observed significant tubulin stabilisation at $3 \mathrm{~nm}$ docetaxel in MMTVPyVmT; Abcc10 $10^{-/-}$cells, whereas MMTV-PyVmt;Abcc10 ${ }^{+/+}$ cells required a higher concentration $(25 \mathrm{nM})$ for a similar effect (Figure 4B). We also examined the wound closure ability of the MMTV-PyVmt;Abcc10 ${ }^{+/+}$compared with MMTVPyVmt;Abcc10 ${ }^{-1-}$ cell lines after docetaxel treatment. We noted a more dramatic effect on cellular migratory activity of $3 \mathrm{nM}$ docetaxel treatment on Abcc10-disrupted lines at 8 and $24 \mathrm{~h}$ post treatment (Figure 4C).

These genotype-associated differences are all compatible with the idea that higher effective concentrations of taxanes accumulate in MMTV-PyVmt;Abcc10 ${ }^{-/-}$cell lines. We incubated mammary cell lines of both genotypes with $0.1 \mu \mathrm{M}\left[{ }^{3} \mathrm{H}\right]$-docetaxel in an 
A
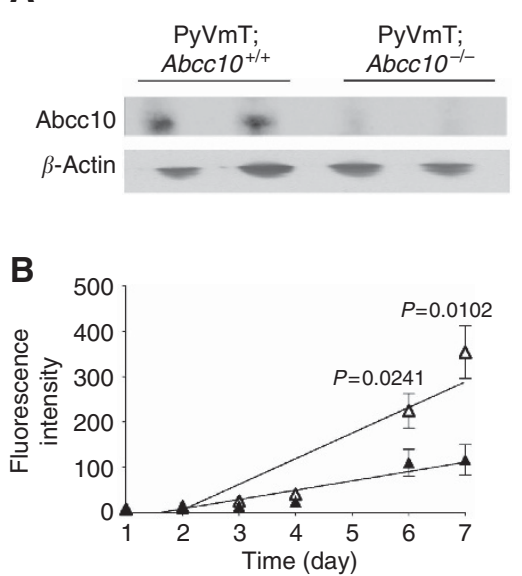

C
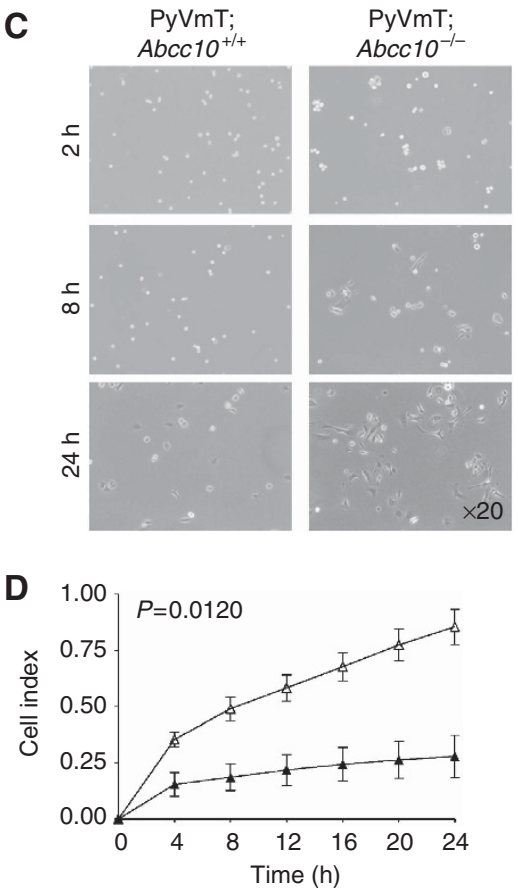

E

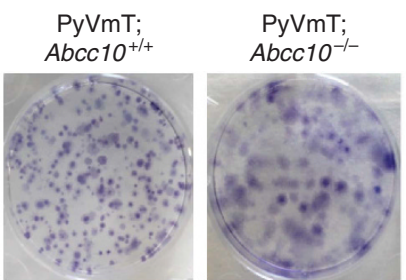

F

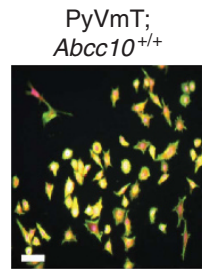

PyVmT;

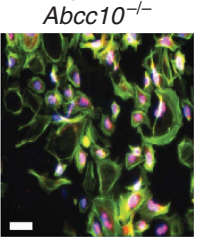

G

PyVmT;
Abcc10 $^{+/+}$

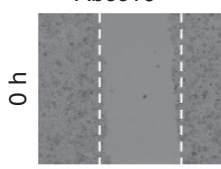

PyVmT;
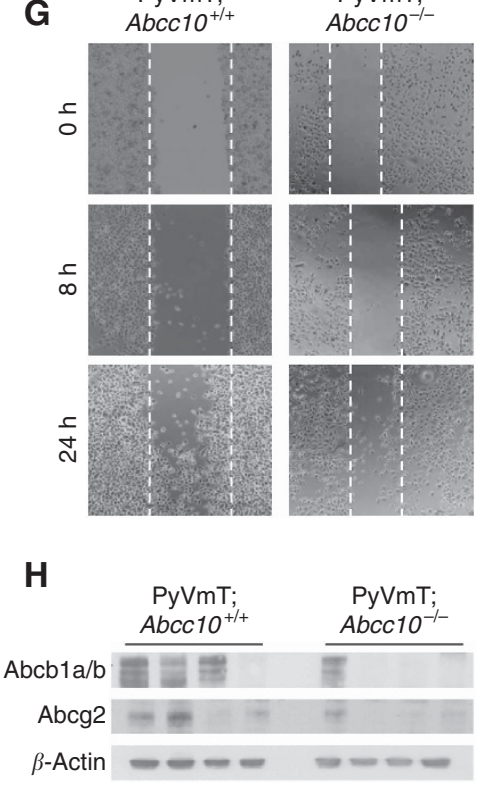
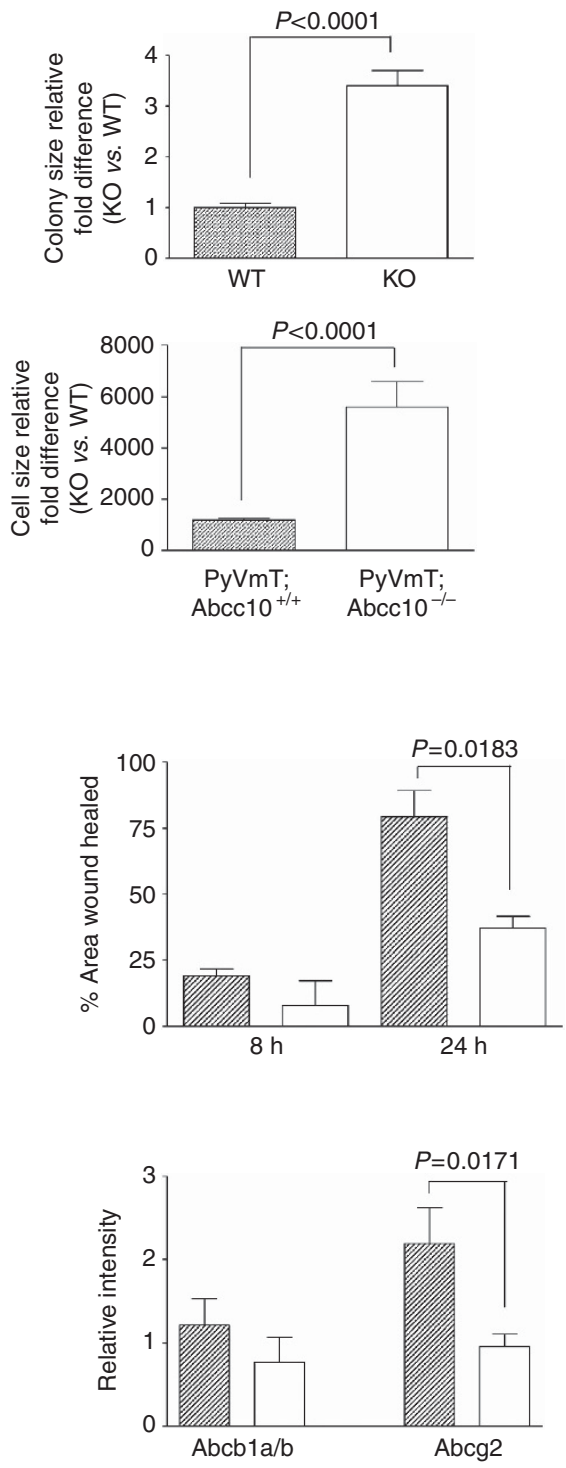

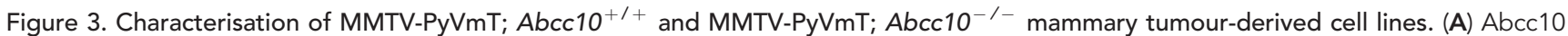

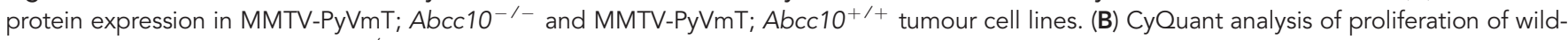
type (black triangle) and Abcc10 ${ }^{-1-}$ (white triangle) cell lines. (C, D) Comparison of the cell-adhesive abilities: Abcc10 wild-type and null cell lines at times 0,8 , and $24 \mathrm{~h}$ after seeding, representative images of are shown (C); monitoring of cell adhesion and spreading with $\times$ CELLigence system. MMTV-PyVmT; Abcc10-/- (open triangles) and MMTV-PyVmT; Abcc10 $10^{+/+}$(closed triangles, shaded) (D, E) Images of colonies formed by

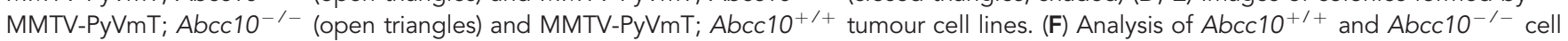
size; phalloidin (green), nuclei (blue), and Deep Red Cell Mask (red). Scale bar, $50 \mu \mathrm{m}$. (G) Wound closure ability of MMTV-PyVmT; Abcc10 ${ }^{+/+}$and MMTV-PyVmT; Abcc10 ${ }^{-/-}$cell lines. (H) Abcb1a/b and Abcg2 protein expression in MMTV-PyVmT; Abcc10 ${ }^{-/-}$and MMTV-PyVmT; Abcc10 $10^{+/+}$ tumour cell lines. Error bars denote mean \pm s.e.m. Statistical significance was determined by two-sided Student's t-test.

accumulation experiment; we observed a $60 \%$ reduction in intracellular accumulation of $\left[{ }^{3} \mathrm{H}\right]$-docetaxel in MMTVPyVmt;Abcc10 $10^{+/+}$compared with MMTV-PyVmt;Abcc10 ${ }^{-/-}$ cell lines (Figure 4D). The amount of reduction in $\left[{ }^{3} \mathrm{H}\right]$-docetaxel is comparable to reduction we published using $\mathrm{ABCC} 10$ transfectants (Malofeeva et al, 2012). Cell cycle analysis showed a marked, dose-dependent G2/M accumulation of MMTV-PyVmt; Abcc10-/mammary tumour cell lines after $48 \mathrm{~h}$ of docetaxel exposure (Figure 5A) or paclitaxel (Figure 5B) but no such accumulation for MMTV-PyVmt;Abcc10 ${ }^{+9}$ cell lines (Figures 5A and B). A 48-h treatment with $25 \mathrm{~nm}$ docetaxel led to a non-statistically significant trend towards early apoptosis in MMTV-PyVmt; $A b c c 10^{-/-}$but not MMTV-PyVmt;Abcc10 $0^{+/+}$cell lines (Figure 5C). Similarly, $25 \mathrm{~nm}$ paclitaxel significantly increased apoptosis in MMTV-PyVmt; $A b c c 10^{-/-}$but not in the MMTVPyVmt;Abcc10 $0^{+/+}$cell lines (Figure 5D).

ABCC10 loss increased the impact of docetaxel treatment in an orthotopic mammary tumour model. An orthotopic mammary tumour model was used to extend our in vitro work to a more clinically relevant in vivo model, offering the additional ability to characterise the cell lines in vitro and in vivo. To determine whether Abcc10 status affects mammary tumour sensitisation to taxanes MMTV-PyVmT; $A b c c 10^{+/+}$and MMTVPyVmT; $A b c c 10^{-1-}$ mammary tumour-derived cells (three cell lines per genotype) were implanted into the mammary gland area of 8 -week-old female mice ( $n=15$ per cell line). Two weeks later, when the tumours grew to $\sim 50 \mathrm{~mm}^{3}$, the mice were divided into 

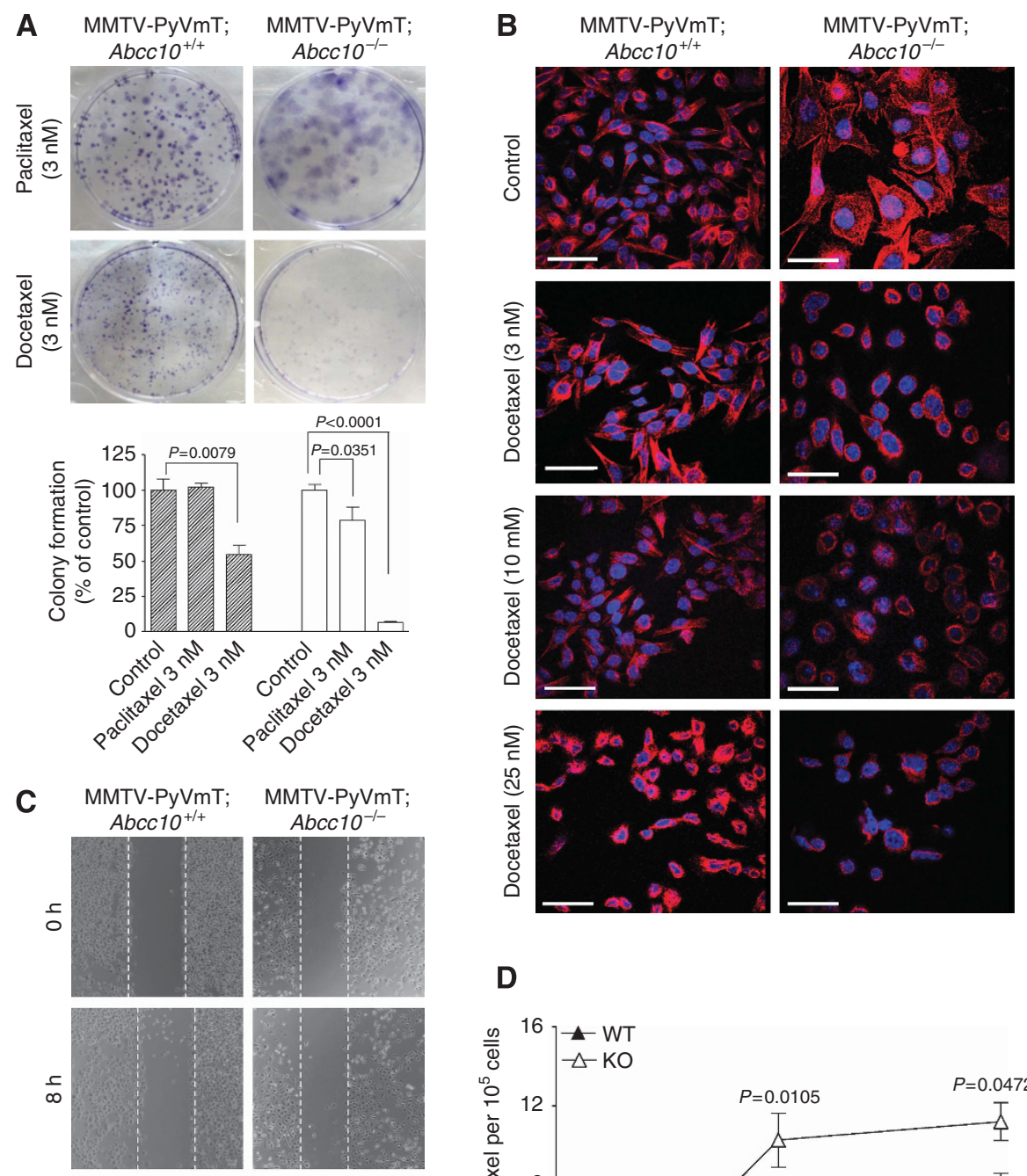

\section{D}
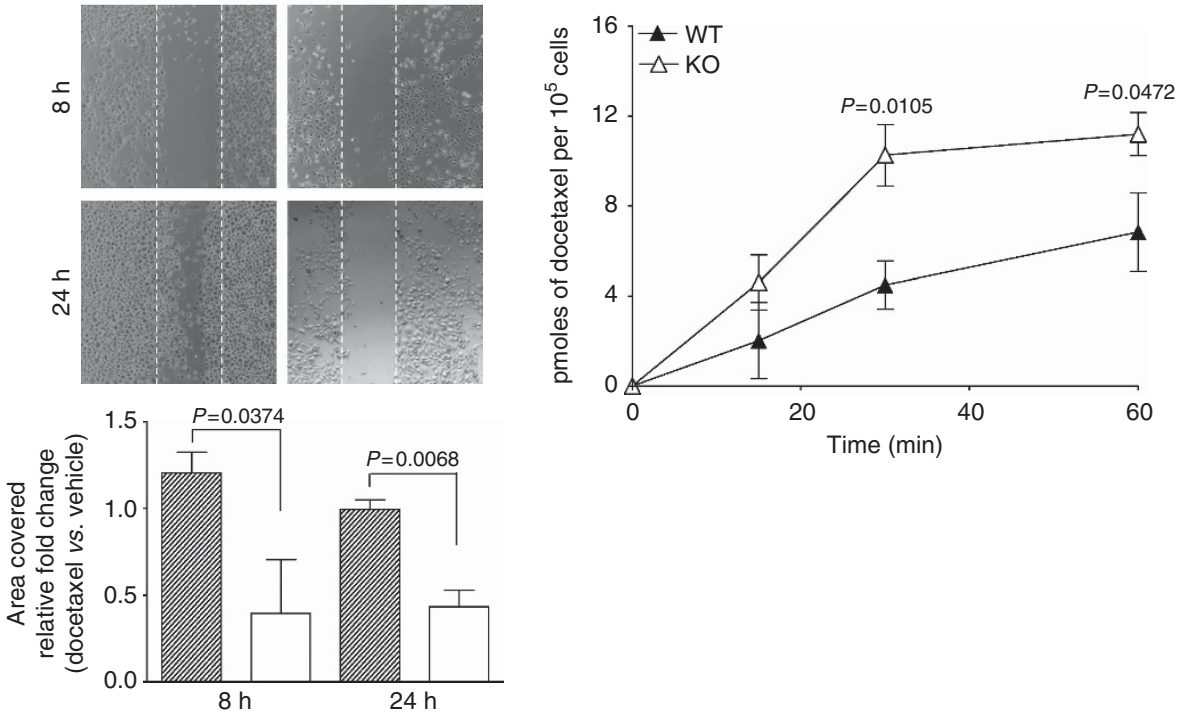

Figure 4. Mammary tumour cell lines originating from PyVmT;Abcc10 null cells are sensitised to cytotoxic ABCC10 substrates. (A) Images of colonies from $\mathrm{Abcc10}^{-/-}$vs $\mathrm{Abcc10^{+/+ }}$ cells following paclitaxel or docetaxel treatment (the analysis with controls is presented on graphs under images). (B) Microtubule staining of Abcc10 wild-type and Abcc10 null cell lines after incubation with 3, 10, or 25 nM of docetaxel; tubulin (red), nuclei (blue). Scale bar, $100 \mu \mathrm{m}$. (C) Images from wound-healing assays assessing the mobility of wild-type and Abcc10 $10^{-1-}$ lines after docetaxel treatment (the analysis with controls is presented on graphs under images). (D) Accumulation of $0.1 \mu \mathrm{M}\left[{ }^{3} \mathrm{H}\right]$-docetaxel in $\mathrm{Abcc} 10^{+/+}$cells $(\mathrm{WT}$, black triangle) compared with the mammary tumour cell lines derived from Abcc10-disrupted mice (KO, white triangle) was observed. Error bars denote mean \pm s.e.m. Statistical significance was determined by two-sided Student's t-test.

two groups: a vehicle control group $(n=5)$ and a $25-\mathrm{mg} \mathrm{kg}^{-1}$ docetaxel treatment group $(n=10)$. The mice were treated weekly by intraperitoneal injection until the tumours reached $200 \mathrm{~mm}^{3}$. As in primary tumour formation, MMTV-PyVmT; $A b c c 10^{-1-}$ tumours grew more rapidly than did MMTV-PyVmT; $A b c c 10^{+/+}$tumours (Figures $6 \mathrm{~A} ; \mathrm{P}=0.001$ ). PyVMT; $A b c c 10^{+/+}$ and $A b c c 10^{-1-}$ tumours were both responsive to docetaxel
$(P=0.003$ and $P<0.001)$. Importantly, over 21 days while MMTV-PyVmT; $A b c c 10^{+/+}$tumour size was reduced by $50 \%$, MMTV-PyVmT; Abcc10 $10^{-1-}$ tumour sensitisation to docetaxel was more dramatic as tumour size was reduced by $86 \%$ compared with untreated mice. To further compare the effectiveness of docetaxel treatment on wild-type and $A b c c 10$ knockout tumours, we analysed the impact of Abcc10 status on proliferation 
A
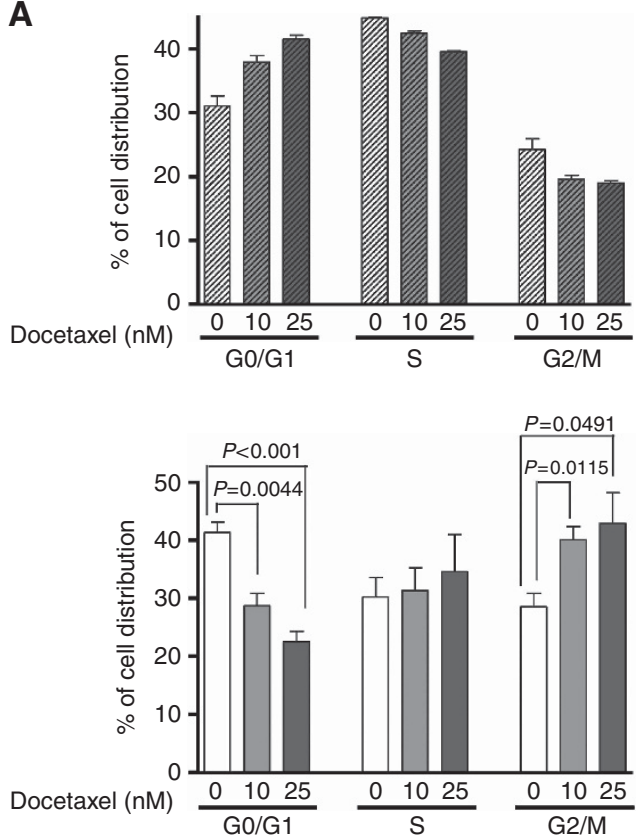

C
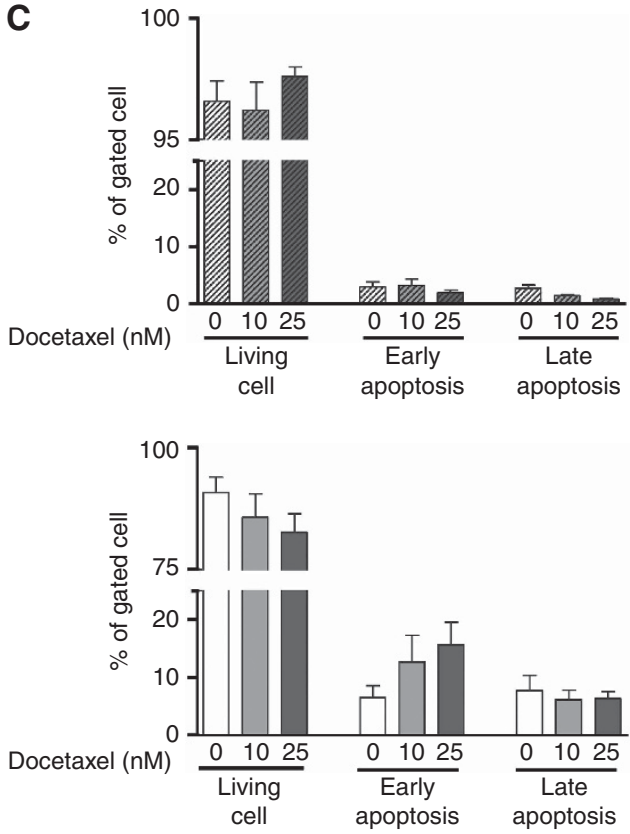

B
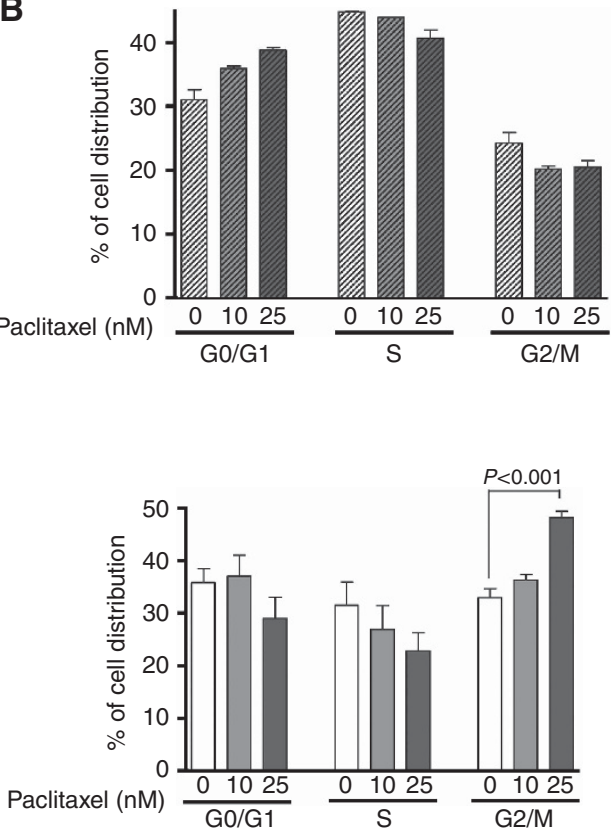

D
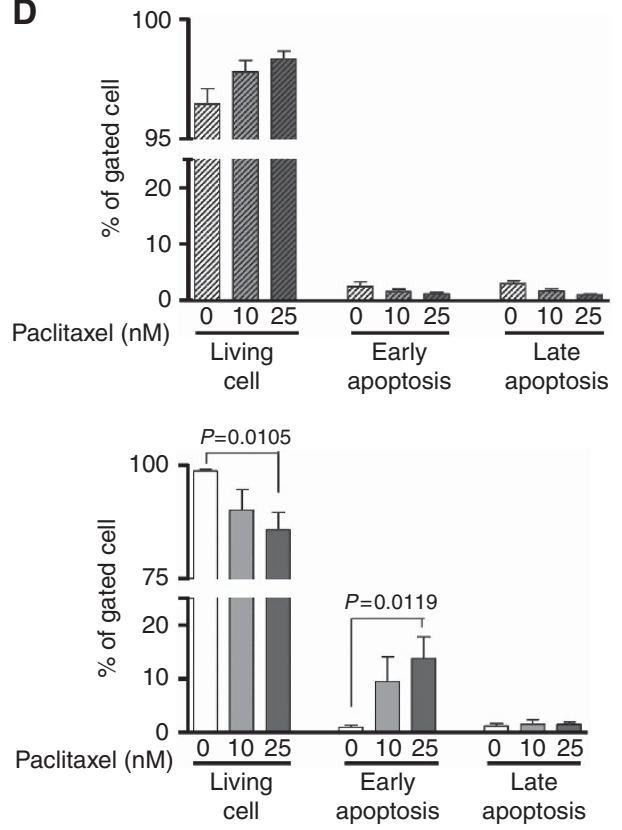

PyVmT;Abcc10 $10^{-1}$

Figure 5. Effects of docetaxel and paclitaxel on cell cycle progression and apoptosis induction in MMTV-PyVT;Abcc10 ${ }^{+/+}$and MMTV-PyVT; Abcc $10^{-/-}$primary mammary tumours cells. After treatment with 0,10 , or $25 \mathrm{~nm}$ docetaxel or paclitaxel, cells were harvested for analysis of cell cycle distribution or apoptosis. Cell cycle distribution is shown after $48 \mathrm{~h}$ of docetaxel (A) or paclitaxel (B) treatment. Percentage of living cells, and early and late apoptosis are shown following $48 \mathrm{~h}$ of docetaxel (C) or paclitaxel (D) treatment. Shade, MMTV-PyVT;Abcc10 $0^{+/+}$cell lines; blank, MMTV-PyVT;Abcc10 ${ }^{-1-}$ cell lines. Error bars denote mean \pm s.e.m. Statistical significance was determined by two-sided Student's t-test.

rate, vascularisation, and apoptosis after docetaxel treatment. The graph represents the relative fold change (Docetaxel vs Vehicle) where vehicle treated is 1 for both wild-type and Abcc10 knockout tumours. We found that $A b c c 10^{-/-}$tumours showed a significant reduction in $\mathrm{Ki}$-67-positive cells (Figure 6C), as well as a reduction in blood vessel density compared with MMTV-PyVmT; $A b c c 10^{+/+}$after treatment (Figure 6D). We also observed that the number of apoptotic cells in treated $A b c c 10$ knockout tumours was increased more than threefold compared with $A b c c 10^{-/-}$ control tumours. Lastly, we saw an increased number of apoptotic cells in $A b c c 10^{-/-}$-treated tumours compared with wild-type treated tumours (Figure 6E).

MMTV-PyVmT;Abcc10 ${ }^{-/-}$mice experienced enhanced docetaxel-dependent therapy and increased overall survival compared with MMTV-PyVmT;Abcc10 ${ }^{+/+}$counterparts. We used the primary MMTV-PyVmT tumour model with $A b c c 10^{-/-}$ and $\mathrm{AbcclO}^{+/+}$genotypes to assess the therapeutic effect of docetaxel in vivo. Mice were treated with vehicle or $25 \mathrm{mg} \mathrm{kg}^{-1}$ of docetaxel weekly for 12 weeks. Mice were also killed if the largest 

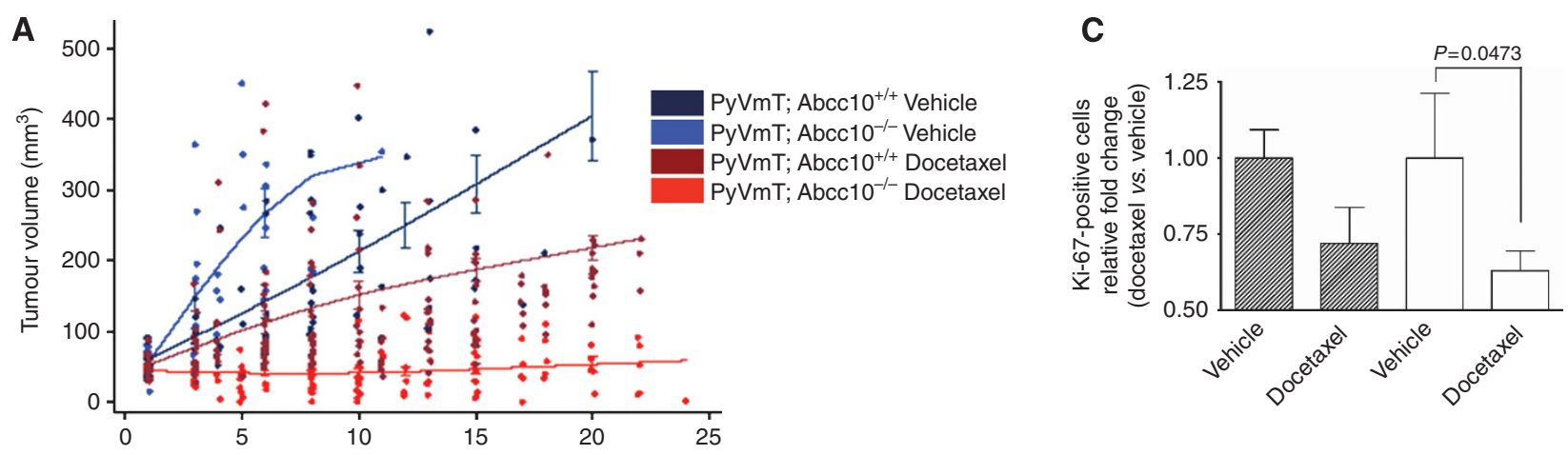

B
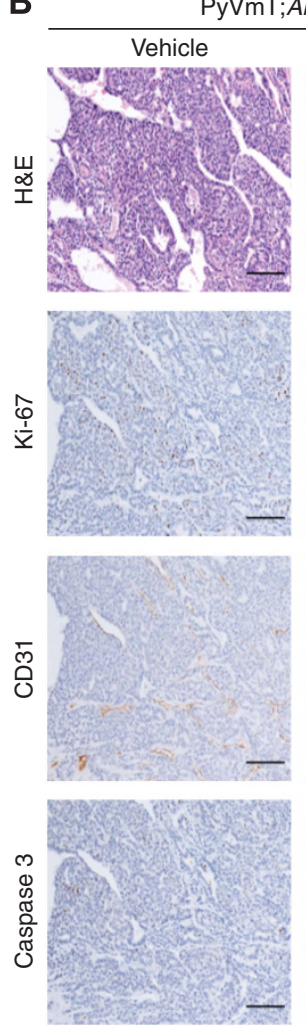
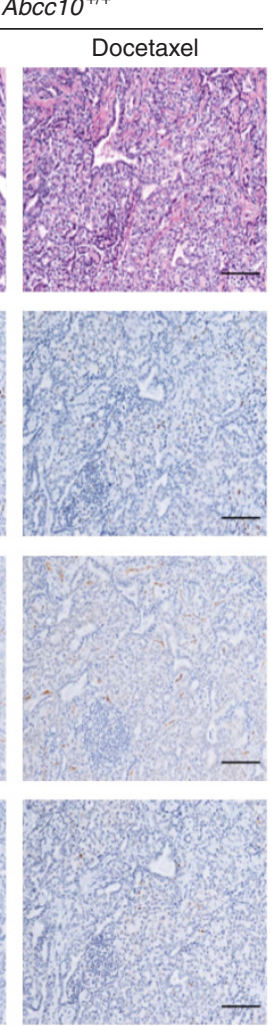

PyVmT; $A b c c 10^{-1-}$
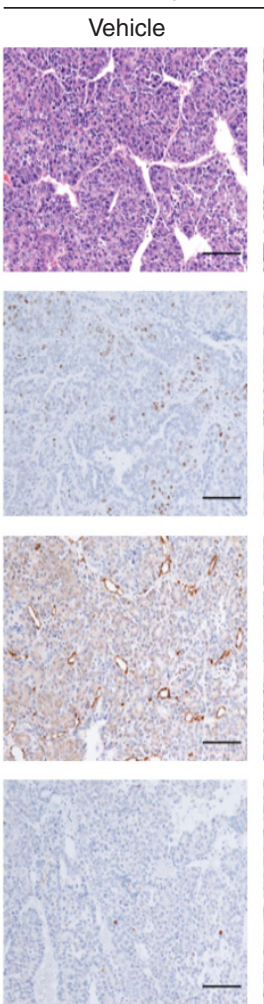
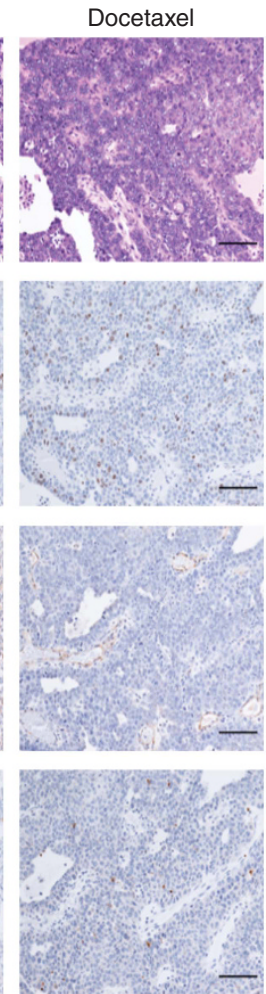

D

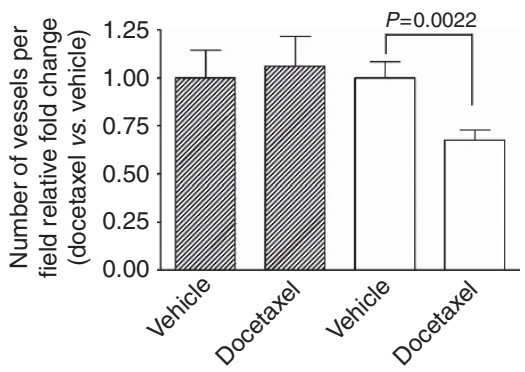

E

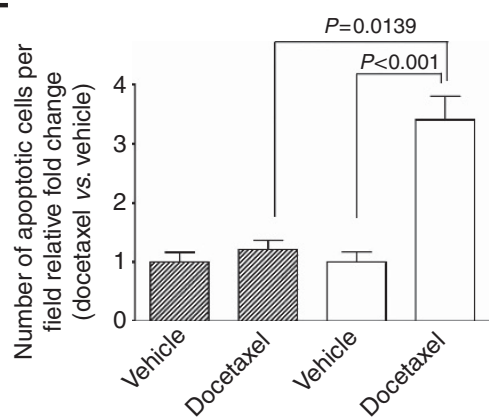

Figure 6. Therapeutic effects of docetaxel on orthotopic mammary tumour model. (A) Allograft model of SCID mice injected with $\mathrm{Abcc}^{-10^{-/-}}$ or wild-type lines treated with docetaxel after tumour development (wild-type: vehicle, grey; docetaxel, brown. Knockout: vehicle, blue; docetaxel, red). (B) Histological and immunohistochemical assessments of Abcc10 wild-type and knockout tumours treated with or without docetaxel at a dosage of $25 \mathrm{mg} \mathrm{kg}^{-1}$ (treated $n=4$, vehicle $n=2$ per genotype). Scale bar, $100 \mu \mathrm{m}$. (C-E) Quantification of the following parameters: proliferation by Ki-67 staining (C), blood vessel density by CD31 staining (D), and apoptosis (E) by Caspase 3 staining. Five high-power fields ( $\times 20$ ) were examined per tumour. Error bars denote mean \pm s.e.m. Statistical significance was determined by two-sided Student's $t$-test.

tumour reached $1000 \mathrm{~mm}^{3}$ or if the total tumour burden was greater than $10 \%$ of body weight (Figure $7 \mathrm{~A}$ and B). MMTVPyVmT; $A b c c 10^{-1-}$ mice were responsive to docetaxel treatment over time $(P=0.006)$ compared with wild-type mice $(P=0.063$; Figure $7 \mathrm{~B})$. Treated wild-type mice reached the study end points and died much earlier compared with MMTV-PyVmT; $\mathrm{Abcc10}^{-/-}$mice treated with docetaxel; at 8 weeks only $44 \%$ of wild-type mice survived in contrast $100 \%$ of Abcc10 knockout mice were still alive. Kaplan-Meier curve analysis indicated significantly increased survival of docetaxel-treated MMTV-PyVmT; $A b c c 10^{-/-}$mice compared with wild-type mice (Figure $7 \mathrm{C}$ ).

\section{DISCUSSION}

In this study, we investigated the impact of ABCC10 loss on breast tumour phenotype and tumour sensitisation using a novel
MMTV-PyVmT; Abcc10 $10^{-/-}$model. Although they grew more rapidly, tumours derived from MMTV-PyVmT; $A b c c 10^{-/-}$mice had decreased apoptosis, blood vessel formation, and lung metastasis in contrast to those from MMTV-PyVmT; $A b c c 10^{+/+}$mice. This was accompanied by numerous differences in the growth properties of cell lines associated with the two genotypes, including most markedly differences in proliferation and migration. Here we showed that cell lines derived from wild-type tumours were less adherent and were more migratory active compared with cell lines derived from Abcc10 null tumours. These characteristics phenocopy the metastatic properties of tumours in vivo. During metastatic disease, cancer cells leave the primary site (reduced adhesion) and go to the secondary environment (migratory activity). Many studies in experimental model systems and in human patients have revealed that alterations in the adhesive and migratory properties of tumour cells correlate with progression to tumour malignancy (Hirohashi, 1998; Cavallaro and Christofori, 2001). 

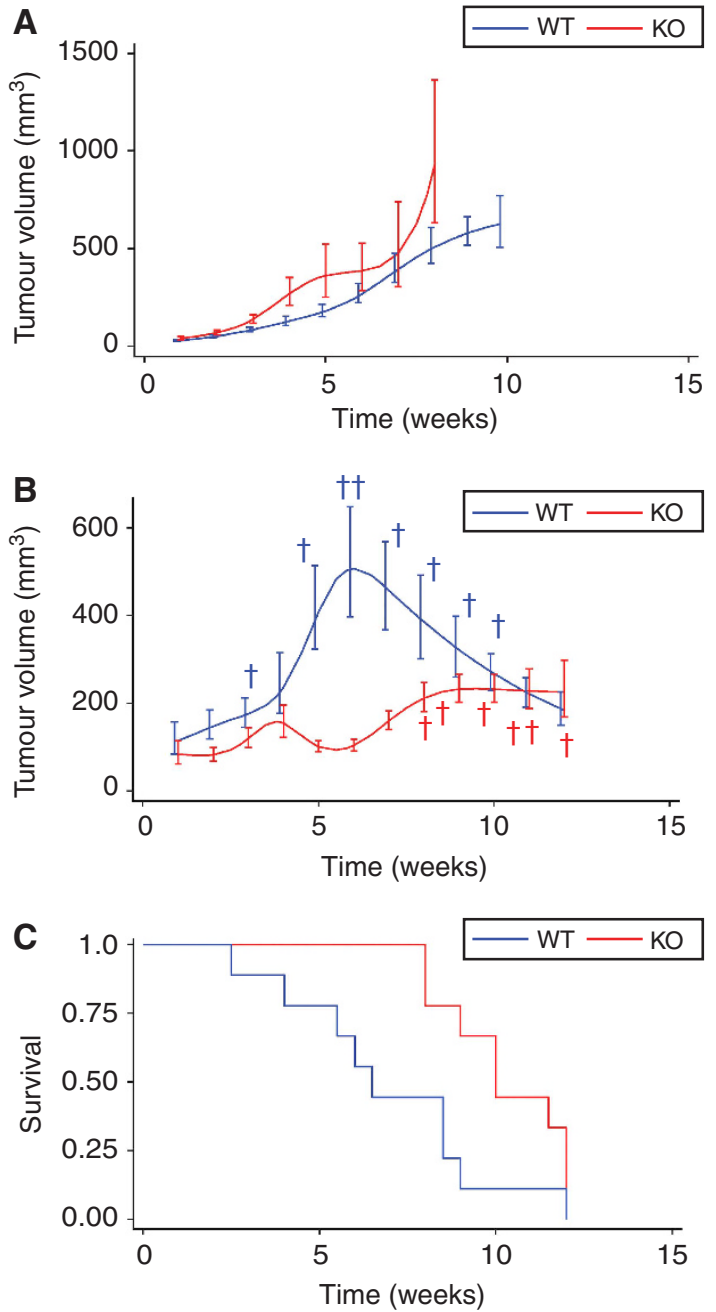

Figure 7. Therapeutic effects of docetaxel on MMTV-PyVmT mice with Abcc10 $10^{-/-}$and $\mathrm{Abcc10}^{+/+}$genotypes. (A) Comparison of growth rates of MMTV-PyVmT;Abcc10 $10^{-1}$ (red line; $\left.n=9\right)$ mammary tumours and MMTV-PyVmT;Abcc10 $0^{+/+}$tumours treated with vehicle (blue line; $n=8)$. (B) Comparison of growth rates of MMTV-PyVmT;Abcc10 $10^{-1-}$ (red line; $n=9$ ) mammary tumours and MMTV-PyVmT;Abcc10 $10^{+/+}$ tumours treated with docetaxel (blue line; $n=9$ ). 'Death. (C) KaplanMeier curve analysis indicated increased survival of docetaxel-treated MMTV-PyVmT;Abcc10 $10^{-1-}$ mice compared with wild-type docetaxeltreated mice $(P=0.0298)$. Error bars denote mean \pm s.e.m.

Taken together, these data imply that, similar to ABCC1 and $\mathrm{ABCC} 3, \mathrm{ABCC} 10$ has important roles beyond controlling drug efflux in mammary tumour biology. We hypothesise that these phenotypes may be related to ABCC10's ability to transport as yet unidentified physiological substrate(s). Alternatively it is possible that $\mathrm{ABCC} 10$ has a role in signalling pathways that mediate processes such as proliferation, malignant transformation, cell survival, and drug resistance. It has been reported previously that inhibition of ABCG2 expression in A549 cells or mixantroneresistant MCF cells by shRNA inhibited proliferation, cell cycle progression. and also modulated the expression of cell cycle regulator genes (Chen et al, 2010). Although the exact mechanisms through which $\mathrm{ABCG} 2$ or $\mathrm{ABCC} 10$ mediate these processes are unknown, prior studies suggest a link between $\mathrm{ABC}$ transporters and MAPK/ERK or PI3K/AKT signalling pathways (Bleau et al, 2009; Hoffmann et al, 2011; Imai et al, 2012; Pick and Wiese, 2012; Huang et al, 2013). Figure 8 illustrates a schematic which summarises the effects of $\mathrm{ABCC} 10$ loss, as well as potential

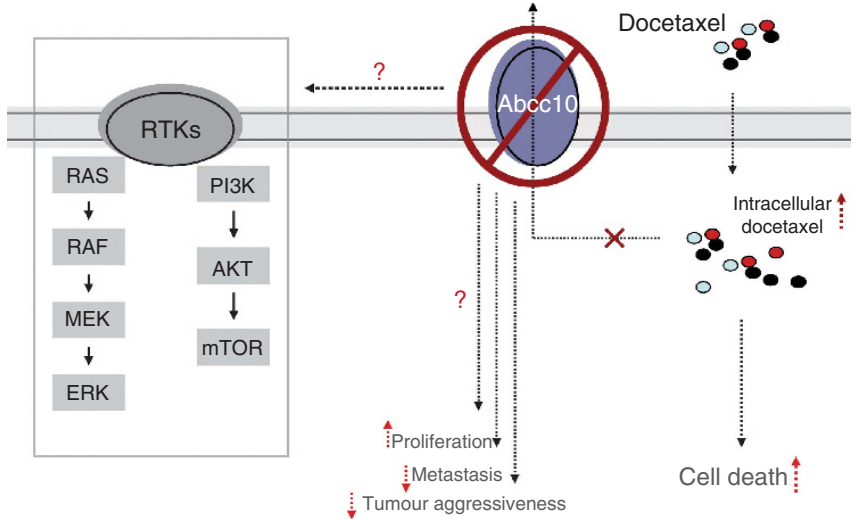

Figure 8. Summary of effects of Abcc10 loss on pathways. Abcc10 loss increased proliferation in vitro and in vivo, decreased number of lung metastasis in MMTV-PyVmT mammary tumour model, and increased drug sensitivity. ABCC10 may be connected to cellular signalling pathways of proliferation and growth.

pathways to investigate in connection with ABCC10 expression. Further studies are required to define the exact mechanisms in which ABCC10 is involved; hence, this area is currently under investigation in our laboratory.

Knowledge of ABCC10 expression is important for understanding the potential effects of this pump's activity in normal and malignant tissues. ABCC10 transcript expression is widespread, with highest levels detected in the gonads and spleen (Hopper-Borge et al, 2009). The ABCC10 transcript has been detected in multiple types of adenocarcinoma that are routinely treated with taxanes, including breast, ovary, and lung (Dabrowska and Sirotnak, 2004; Takayanagi et al, 2004). ABCC10 transcript has also been found in hepatocellular carcinoma (Borel et al, 2012) and colorectal tumours (Hlavata et al, 2012). Recent work has shown that ABCC10 is among the transporters that are upregulated in pancreatic adenocarcinoma tumours compared with normal tissue and the idea was put forth that ABCC10 might contribute to poor treatment response in this tumour type (Mohelnikova-Duchonova et al, 2013). Another paper compared the absolute gene expression of all the human xenobiotic transporter genes in various tissue types and tumours. These authors demonstrated that ABCC10 expression in tumours derived from lung, colon, and breast was relatively high in terms of absolute intensity (Bleasby et al, 2006). However, only few studies have been published regarding $\mathrm{ABCC} 10$ protein expression. Immunohistochemical staining of normal and tumour tissues revealed that $\mathrm{ABCC} 10$ is upregulated in cancer compared with the normal lung (Wang et al, 2009). ABCC10 protein expression was also evaluated in two human head and neck cancer cell lines, SCCHA and HSY. ABCC10 was not detected in the parental cell lines. However, after vincristine treatment ABCC10 was upregulated in the HSY cell line (Naramoto et al, 2007).

In this report we demonstrate that $\mathrm{ABCC} 10$ is expressed in various breast cancer lines and importantly that it is expressed in clinical samples derived from several breast cancer molecular subtypes. Further, we showed that ABCC10 is more highly expressed in HER2 + and ER + human breast cancer cell lines. Analysis of human tumour tissue also showed higher expression of $\mathrm{ABCC} 10$ in HER2 + and ER + tumours. Interestingly, the triplenegative breast cancer subtype was more heterogeneous for ABCC10 expression compared with other subtypes. This observation suggests that it may be prudent to investigate ABCC10 as a novel potential target for clinical screening of triple-negative breast cancer as this information could support the development of more personalised therapies. Further, triple-negative breast cancer has 
the worst prognosis of the breast cancer subtypes and affects African American women disproportionately (Stead et al, 2009). It is of considerable interest to assess $\mathrm{ABCC} 10$ protein expression in African American women to determine whether ABCC10 expression is linked to health disparities in response to treatment.

We recently demonstrated that $\mathrm{ABCC} 10$ transporter activity is inhibited by sorafenib, a multitargeted tyrosine kinase inhibitor currently in use for the treatment of renal cell carcinoma and other cancers (Malofeeva et al, 2012). At this time, there are no identified inhibitors with specific, in vivo efficacy against endogenous ABCC10; an important goal for future work would be the exploration of the ability of sorafenib, cepharanthine, and other putative inhibitors to modulate in vivo taxane transport capabilities of $\mathrm{ABCC} 10$ in relevant preclinical models. ABCC10 inhibition is particularly nominated as a potentially high-value target for inhibition based on its physiological relevance to in vivo taxane resistance in breast cancer. Whether absence of ABCC10 sensitises solid tumours to taxanes while not leading to unacceptable toxicity in normal tissue remains to be determined (Burkhart et al, 2009). In summary, we showed that $\mathrm{ABCC} 10$ does not only modulate drug transport but has an impact on tumour biology. For better understanding of the mechanisms by which Abcc10 influences proliferation, migration, and metastasis, further investigation will be required. Importantly, we also showed that elimination of endogenous Abcc10 has a profound effect on tumour sensitization to taxanes and overall survival. This work emphasises the value of future studies of $\mathrm{ABCC} 10$ in breast cancer pathogenesis and resistance to treatment.

\section{ACKNOWLEDGEMENTS}

This work was supported by the FCCC Laboratory Animal, Transgenic, High Throughput Screening, Cell Culture, Biosample Repository, Biomedical Imaging, Histopathology, Biostatistics and Bioinformatics Facilities. We thank Drs Denise C Connolly and Erica A Golemis (Fox Chase Cancer Center) for helpful discussions. We also acknowledge Dr Erica A Golemis for critical review of the manuscript. This work was supported by the National Institutes of Health grants K01CA120091 and R21 CA150770 to EHB, CA06927 to Fox Chase Cancer Center and Ruth L. Kirschstein National Research Service Award 5T32CA009035-37 to JWT.

\section{CONFLICT OF INTEREST}

The authors declare no conflict of interest.

\section{REFERENCES}

Amiri-Kordestani L, Basseville A, Kurdziel K, Fojo AT, Bates SE (2013) Targeting MDR in breast and lung cancer: discriminating its potential importance from the failure of drug resistance reversal studies. Drug Resist Updat 15(1-2): 50-61.

Bleasby K, Castle JC, Roberts CJ, Cheng C, Bailey WJ, Sina JF, Kulkarni AV, Hafey MJ, Evers R, Johnson JM, Ulrich RG, Slatter JG (2006) Expression profiles of 50 xenobiotic transporter genes in humans and pre-clinical species: a resource for investigations into drug disposition. Xenobiotica 36(10-11): 963-988.

Bleau AM, Hambardzumyan D, Ozawa T, Fomchenko EI, Huse JT, Brennan CW, Holland EC (2009) PTEN/PI3K/Akt pathway regulates the side population phenotype and ABCG2 activity in glioma tumor stem-like cells. Cell Stem Cell 4(3): 226-235.

Bolstad BM, Irizarry RA, Astrand M, Speed TP (2003) A comparison of normalization methods for high density oligonucleotide array data based on variance and bias. Bioinformatics 19(2): 185-193.
Borel F, Han R, Visser A, Petry H, van Deventer SJ, Jansen PL, Konstantinova P. Reseau Centre de Ressources Biologiques Foie F (2012) Adenosine triphosphate-binding cassette transporter genes up-regulation in untreated hepatocellular carcinoma is mediated by cellular microRNAs. Hepatology 55(3): 821-832.

Burkhart CA, Watt F, Murray J, Pajic M, Prokvolit A, Xue C, Flemming C, Smith J, Purmal A, Isachenko N, Komarov PG, Gurova KV, Sartorelli AC, Marshall GM, Norris MD, Gudkov AV, Haber M (2009) Small-molecule multidrug resistance-associated protein 1 inhibitor reversan increases the therapeutic index of chemotherapy in mouse models of neuroblastoma. Cancer Res 69(16): 6573-6580.

Cai KQ, Wu H, Klein-Szanto AJ, Xu XX (2009) Acquisition of a second mutation of the Tp53 alleles immediately precedes epithelial morphological transformation in ovarian tumorigenicity. Gynecol Oncol 114(1): 18-25.

Cavallaro U, Christofori G (2001) Cell adhesion in tumor invasion and metastasis: loss of the glue is not enough. Biochim Biophys Acta 1552(1): 39-45.

Chen Z, Liu F, Ren Q, Zhao Q, Ren H, Lu S, Zhang L, Han Z (2010) Suppression of ABCG2 inhibits cancer cell proliferation. Int J Cancer 126(4): 841-851.

Dabrowska M, Sirotnak FM (2004) Regulation of transcription of the human MRP7 gene. Characteristics of the basal promoter and identification of tumor-derived transcripts encoding additional $5^{\prime}$ end heterogeneity. Gene 341: 129-139.

Dave B, Mittal V, Tan NM, Chang JC (2012) Epithelial-mesenchymal transition, cancer stem cells and treatment resistance. Breast Cancer Res 14(1): 202.

Forrester E, Chytil A, Bierie B, Aakre M, Gorska AE, Sharif-Afshar AR, Muller WJ, Moses HL (2005) Effect of conditional knockout of the type II TGF-beta receptor gene in mammary epithelia on mammary gland development and polyomavirus middle $\mathrm{T}$ antigen induced tumor formation and metastasis. Cancer Res 65(6): 2296-2302.

Glavinas H, Krajcsi P, Cserepes J, Sarkadi B (2004) The role of ABC transporters in drug resistance, metabolism and toxicity. Curr Drug Deliv 1(1): $27-42$.

Grassilli E, Narloch R, Federzoni E, Ianzano L, Pisano F, Giovannoni R, Romano G, Masiero L, Leone BE, Bonin S, Donada M, Stanta G, Helin K, Lavitrano M (2013) Inhibition of GSK3B Bypass drug resistance of p53-Null colon carcinomas by enabling necroptosis in response to chemotherapy. Clin Cancer Res 19(14): 3820-3831.

Guy CT, Webster MA, Schaller M, Parsons TJ, Cardiff RD, Muller WJ (1992) Expression of the neu protooncogene in the mammary epithelium of transgenic mice induces metastatic disease. Proc Natl Acad Sci USA 89(22): 10578-10582.

Harrell FE (2001) Regression Modeling Strategies. In Chapter 2, pp 11-40. Springer: New York, NY.

Henderson MJ, Haber M, Porro A, Munoz MA, Iraci N, Xue C, Murray J, Flemming CL, Smith J, Fletcher JI, Gherardi S, Kwek CK, Russell AJ, Valli E, London WB, Buxton AB, Ashton LJ, Sartorelli AC, Cohn SL, Schwab M, Marshall GM, Perini G, Norris MD (2011) ABCC multidrug transporters in childhood neuroblastoma: clinical and biological effects independent of cytotoxic drug efflux. J Natl Cancer Inst 103(16): 1236-1251.

Higgins MJ, Baselga J (2011) Targeted therapies for breast cancer. J Clin Invest 121(10): 3797-3803.

Hirohashi S (1998) Inactivation of the E-cadherin-mediated cell adhesion system in human cancers. Am J Pathol 153(2): 333-339.

Hlavac V, Brynychova V, Vaclavikova R, Ehrlichova M, Vrana D, Pecha V, Kozevnikovova R, Trnkova M, Gatek J, Kopperova D, Gut I, Soucek P (2013) The expression profile of ATP-binding cassette transporter genes in breast carcinoma. Pharmacogenomics 14(5): 515-529.

Hlavata I, Mohelnikova-Duchonova B, Vaclavikova R, Liska V, Pitule P, Novak P, Bruha J, Vycital O, Holubec L, Treska V, Vodicka P, Soucek P (2012) The role of ABC transporters in progression and clinical outcome of colorectal cancer. Mutagenesis 27(2): 187-196.

Hoffmann K, Shibo L, Xiao Z, Longerich T, Buchler MW, Schemmer P (2011) Correlation of gene expression of ATP-binding cassette protein and tyrosine kinase signaling pathway in patients with hepatocellular carcinoma. Anticancer Res 31(11): 3883-3890.

Hopper-Borge E, Chen ZS, Shchaveleva I, Belinsky MG, Kruh GD (2004) Analysis of the drug resistance profile of multidrug resistance protein 7 (ABCC10): resistance to docetaxel. Cancer Res 64(14): 4927-4930. 
Hopper-Borge E, Xu X, Shen T, Shi Z, Chen ZS, Kruh GD (2009) Human multidrug resistance protein 7 (ABCC10) is a resistance factor for nucleoside analogues and epothilone B. Cancer Res 69(1): 178-184.

Hopper-Borge EA, Churchill T, Paulose C, Nicolas E, Jacobs JD, Ngo O, Kuang Y, Grinberg A, Westphal H, Chen ZS, Klein-Szanto AJ, Belinsky MG, Kruh GD (2011) Contribution of Abcc10 (Mrp7) to in vivo paclitaxel resistance as assessed in Abcc10 $(-/-)$ mice. Cancer Res 71(10): 3649-3657.

Hopper E, Belinsky MG, Zeng H, Tosolini A, Testa JR, Kruh GD (2001) Analysis of the structure and expression pattern of MRP7 (ABCC10), a new member of the MRP subfamily. Cancer Lett 162(2): 181-191.

Huang FF, Wu DS, Zhang L, Yu YH, Yuan XY, Li WJ, Chen XP, Zhao XL, Chen FP, Zeng H (2013) Inactivation of PTEN increases ABCG2 expression and the side population through the PI3K/Akt pathway in adult acute leukemia. Cancer Lett 336(1): 96-105.

Huisman MT, Chhatta AA, van Tellingen O, Beijnen JH, Schinkel AH (2005) MRP2 (ABCC2) transports taxanes and confers paclitaxel resistance and both processes are stimulated by probenecid. Int J Cancer 116(5): 824-829.

Imai Y, Yamagishi H, Ono Y, Ueda Y (2012) Versatile inhibitory effects of the flavonoid-derived PI3K/Akt inhibitor, LY294002, on ATP-binding cassette transporters that characterize stem cells. Clin Transl Med 1(1): 24.

Ishihara D, Dovas A, Hernandez L, Pozzuto M, Wyckoff J, Segall JE, Condeelis JS, Bresnick AR, Cox D (2013) Wiskott-Aldrich syndrome protein regulates leukocyte-dependent breast cancer metastasis. Cell Rep 4(3): 429-436.

Izumchenko E, Singh MK, Plotnikova OV, Tikhmyanova N, Little JL, Serebriiskii IG, Seo S, Kurokawa M, Egleston BL, Klein-Szanto A, Pugacheva EN, Hardy RR, Wolfson M, Connolly DC, Golemis EA (2009) NEDD9 promotes oncogenic signaling in mammary tumor development. Cancer Res 69(18): 7198-7206.

Kelly RJ, Robey RW, Chen CC, Draper D, Luchenko V, Barnett D, Oldham RK, Caluag Z, Frye AR, Steinberg SM, Fojo T, Bates SE (2012) A pharmacodynamic study of the P-glycoprotein antagonist CBT-1(R) in combination with paclitaxel in solid tumors. Oncologist 17(4): 512.

Keppler D (2011) Multidrug resistance proteins (MRPs, ABCCs): importance for pathophysiology and drug therapy. Handb Exp Pharmacol 201: 299-323.

Kononen J, Bubendorf L, Kallioniemi A, Barlund M, Schraml P, Leighton S, Torhorst J, Mihatsch MJ, Sauter G, Kallioniemi OP (1998) Tissue microarrays for high-throughput molecular profiling of tumor specimens. Nat Med 4(7): 844-847.

Kuo PL, Hsu YL, Cho CY (2006) Plumbagin induces G2-M arrest and autophagy by inhibiting the AKT/mammalian target of rapamycin pathway in breast cancer cells. Mol Cancer Ther 5(12): 3209-3221.

Lin EY, Jones JG, Li P, Zhu L, Whitney KD, Muller WJ, Pollard JW (2003) Progression to malignancy in the polyoma middle $\mathrm{T}$ oncoprotein mouse breast cancer model provides a reliable model for human diseases. Am J Pathol 163(5): 2113-2126.

Malofeeva E, Domanitskaya N, Gudima M, Hopper-Borge EA (2012) Modulation of the ATPase and transport activities of broad-acting multidrug resistance factor ABCC10 (MRP7). Cancer Res 72(24): 6457-6467.

Marcotte R, Smith HW, Sanguin-Gendreau V, McDonough RV, Muller WJ (2012) Mammary epithelial-specific disruption of c-Src impairs cell cycle progression and tumorigenesis. Proc Natl Acad Sci USA 109(8): 2808-2813.

McMillin DW, Negri JM, Mitsiades CS (2013) The role of tumour-stromal interactions in modifying drug response: challenges and opportunities. Nat Rev Drug Discov 12(3): 217-228.

Mohelnikova-Duchonova B, Brynychova V, Oliverius M, Honsova E, Kala Z, Muckova K, Soucek P (2013) Differences in transcript levels of ABC transporters between pancreatic adenocarcinoma and nonneoplastic tissues. Pancreas 42(4): 707-716.

Naramoto H, Uematsu T, Uchihashi T, Doto R, Matsuura T, Usui Y, Uematsu S, Li X, Takahashi M, Yamaoka M, Furusawa K (2007) Multidrug resistance-associated protein 7 expression is involved in crossresistance to docetaxel in salivary gland adenocarcinoma cell lines. Int $J$ Oncol 30(2): 393-401.

O'Donovan N, Crown J, Stunell H, Hill AD, McDermott E, O'Higgins N, Duffy MJ (2003) Caspase 3 in breast cancer. Clin Cancer Res 9(2): 738-742.

Oguri T, Ozasa H, Uemura T, Bessho Y, Miyazaki M, Maeno K, Maeda H, Sato S, Ueda R (2008) MRP7/ABCC10 expression is a predictive biomarker for the resistance to paclitaxel in non-small cell lung cancer. Mol Cancer Ther 7(5): 1150-1155.

Parsons M, Heike G (2009) How to make tissue microarrays. Diagn Histopathol 15(3): 142-149.

Pick A, Wiese M (2012) Tyrosine kinase inhibitors influence ABCG2 expression in EGFR-positive MDCK BCRP cells via the PI3K/Akt signaling pathway. ChemMedChem 7(4): 650-662.

Shults J, Ratcliffe SJ, Leonard M (2007) Improved generalized estimating equation analysis via xtqls for implementation of quasi-least squares in Stata. Strata J 7(2): 147-166.

Smyth GK (2004) Linear models and empirical bayes methods for assessing differential expression in microarray experiments. Stat Appl Genet Mol Biol 3: Article 3.

Soerjomataram I, Louwman MW, Ribot JG, Roukema JA, Coebergh JW (2008) An overview of prognostic factors for long-term survivors of breast cancer. Breast Cancer Res Treat 107(3): 309-330.

Stead LA, Lash TL, Sobieraj JE, Chi DD, Westrup JL, Charlot M, Blanchard RA, Lee JC, King TC, Rosenberg CL (2009) Triple-negative breast cancers are increased in black women regardless of age or body mass index. Breast Cancer Res 11(2): R18.

Sui M, Huang Y, Park BH, Davidson NE, Fan W (2007) Estrogen receptor alpha mediates breast cancer cell resistance to paclitaxel through inhibition of apoptotic cell death. Cancer Res 67(11): 5337-5344.

Szakacs G, Annereau JP, Lababidi S, Shankavaram U, Arciello A, Bussey KJ, Reinhold W, Guo Y, Kruh GD, Reimers M, Weinstein JN, Gottesman MM (2004) Predicting drug sensitivity and resistance: profiling ABC transporter genes in cancer cells. Cancer Cell 6(2): 129-137.

Takayanagi S, Kataoka T, Ohara O, Oishi M, Kuo MT, Ishikawa T (2004) Human ATP-binding cassette transporter ABCC10: expression profile and p53-dependent upregulation. J Exp Ther Oncol 4(3): 239-246.

Ueno NT, Yu D, Hung MC (1997) Chemosensitization of HER-2/neuoverexpressing human breast cancer cells to paclitaxel (Taxol) by adenovirus type 5 E1A. Oncogene 15(8): 953-960.

Wang P, Zhang Z, Gao K, Deng Y, Zhao J, Liu B, Li X (2009) Expression and clinical significance of ABCC10 in the patients with non-small cell lung cancer.. Zhongguo Fei Ai Za Zhi 12(8): 875-878.

Woodward EJ, Twelves C (2010) Scheduling of taxanes: a review. Curr Clin Pharmacol 5(3): 226-231.

Yamada A, Ishikawa T, Ota I, Kimura M, Shimizu D, Tanabe M, Chishima T, Sasaki T, Ichikawa Y, Morita S, Yoshiura K, Takabe K, Endo I (2013) High expression of ATP-binding cassette transporter ABCC11 in breast tumors is associated with aggressive subtypes and low disease-free survival. Breast Cancer Res Treat 137(3): 773-782.

(c) (1) (2) This work is licensed under the Creative Commons Attribution-NonCommercial-Share Alike 3.0 Unported License. To view a copy of this license, visit http://creativecommons. org/licenses/by-nc-sa/3.0/

Supplementary Information accompanies this paper on British Journal of Cancer website (http://www.nature.com/bjc) 